\title{
PEMANFAATAN ECENG GONDOK UNTUK PEMBERDAYAAN EKONOMI MASYARAKAT DI DESA JELAPAT I KABUPATEN BARITO KUALA
}

\author{
Isna Wardiah', Helmy Noor', Reza Fauzan ${ }^{3}$, Fuad Sholihin $^{4}$ \\ Politeknik Negeri Banjarmasin ${ }^{1,2,3,4}$ \\ Isnawardiah@poliban.ac.id ${ }^{l}$
}

\begin{abstract}
The partner in this community service activity is a resident of Jelapat I village, Barito Kuala Regency. The problem with partners is that most of the partner communities are at the middle to lower economic level, they work as farmers who do not own their own land. The partner village is in the Barito river basin which is the foundation of people's lives, one of which is a means of transportation, but the condition of the Barito River is currently polluted. One reason is a large amount of Eceng Gondok (Eichhornia crassipes) in the river so that it becomes a weed that disrupts water transportation. The solution offered is in the form of socialization and workshop on eceng gondok processing into economically valuable handicrafts so that it can increase the income of partners, as well as training for marketing strategies so that partners can later market their products. The output of this activity is in the form of partner creativity in processing eceng gondok into handicraft items, as well as articles in community service journals

Keywords: Eceng gondok, Economic empowerment, resident of Jelapat I village
\end{abstract}

\begin{abstract}
ABSTRAK
Mitra pada kegiatan pengabdian masyarakat ini adalah warga desa Jelapat I Kabupaten Barito Kuala. Permasalahan pada mitra bahwa sebagian besar masyarakat mitra berada pada level ekonomi menengah kebawah, mereka berprofesi sebagai petani yang tidak memiliki lahan sendiri. Desa mitra berada pada daerah aliran sungai Barito yang merupakan tumpuan hidup masyarakat, salah satunya sebagai sarana transportasi, namun kondisi sungai barito saat ini sudah tercemar. Salah satu penyebabnya adalah banyaknya Eceng gondok di sungai sehingga menjadi gulma yang menggangu transportasi air. Solusi yang ditawarkan berupa sosialisasi dan workshop pengolahan eceng gondok menjadi barang kerajinan yang bernilai ekonomis sehingga menambah penghasilan mitra, serta pelatihan untuk strategi pemasarannya agar mitra nantinya dapat madiri memasarkan produknya. Luaran dari kegiatan ini berupa kreatifitas mitra dalam pengolahan eceng gondok menjadi barang kerajinan, serta artikel pada jurnal pengabdian masyarakat Kata Kunci: Eceng Gondok, Pemberdayaan ekonomi, Masyarakat Jelapat I
\end{abstract}

\section{PENDAHULUAN}

\section{Analisis Situasi}

Sungai merupakan tumpuan hidup sebagian besar masyarakat yang bermukim di Kalimantan Selatan (Kalsel). Salah satu sungai terpanjang di provinsi ini adalah sungai Barito. Sungai barito memegang peranan besar dalam peradapan masyarakat Kalsel, baik dari segi kebudayaan, keagamaan, hingga 
perekonomian. Perannya sebagai tol perairan tentu tidak dapat digerus oleh kemajuan zaman.

Salah satu desa yang berada di pinggir aliran sungai Barito adalah desa Jelapat I. Desa ini terletak di kecamatan Tamban, kabupaten Barito Kuala, provinsi Kalimantan Selatan. Jarak dari Kota Banjarmasin ke Desa Jelapat I sekitar 20 menit jika menggunakan kapal motor (feri). Lokasinya strategis karena memiliki pelabuhan feri yang menjadikan Desa jelapat dilalui orang yang ingin ke Kecamatan Tamban. Jumlah penduduk 6703 orang dengan laki-laki 3355 orang dan perempuan 3348 orang, yang terdiri dari 2064 kepala keluarga (data desa jelapat I, 2018). Sebagian besar penduduk di desa ini berprofesi sebagai petani.

Sebagaimana desa lainnya yang berada di daerah aliran sungai (DAS) Barito, sungai merupakan tumpuan kehidupan sebagian besar masyarakatnya. Namun sangat disayangkan, keadaan sungai barito saat ini sudah tidak sejaya masa lalunya. Sampah, cemaran industri, dan pertambangan diduga menjadi penyebab memburuknya kondisi sungai barito (hasanzainuddin, 2017). Padahal, sungai tidak hanya digunakan sebagai sarana transportasi, tapi juga tempat mandi dan mencuci (MCK).

\section{Permasalahan Mitra}

Berdasarkan hasil pengamatan dan wawancara yang dilakukan, diketahui bahwa sebagian besar masyarakat di desai jelapat I yang memiliki luas kurang lebih 18 kilometer persegi ini berada pada golongan ekonomi menengah kebawah. Dengan jumlah penduduk kurang lebih 6703 orang, sebagian besar mata pencahariannya adalah sebagai petani. Namun yang jadi permasalahan adalah lahan yang ditanami masyarakat adalah tanah milik perusahaan yang kapan saja bisa diambil oleh perusahaan tersebut, hal ini menyebabkan kondisi ekonomi masyarakat semakin riskan.

Disisi lain, Salah satu kondisi nyata yang kami lihat berdasarkan observasi lapangan adalah banyaknya tanaman eceng gondok yang berada di bantaran sungai di desa ini. Padahal masyarakat masih banyak yang menggunakan kapal klotok atau speedboat sebagai sarana transportasi. Banyaknya eceng gondok menyebabkan kapal terkadang sulit melintas karena baling baling mesin tersangkut akar. Selain itu, banyaknya sampah yang tersangkut di tanaman ini, menyebabkan kodisi sungai menjadi kelihatan kotor. Pada saat musim pnghujan tiba, jumlah eceng gondok di sungai akan meningkat tajam, bahkan menurut penuturan salah seorang warga yang biasa mengambil air sungai untuk kebutuhan MCK, untuk menimba air saja sulit karena padatnya jumlah eceng gondok di permukaan sungai.

Secara garis besar, permasalahan masyarakat di desa jelapat I Kecamatan Tamban selaku mitra adalah sebagai berikut:

1) Mitra berada pada level ekonomi menengah kebawah. Sebagian besar bermata pencaharian sebagai petani yang tidak memiliki lahan sendiri sehingga secara ekonomi sangat riskan 
2) Sungai barito, dimana desa mitra berada pada daerah aliran sungainya (DAS) telah tercemar dan banyak sekali ditumbuhi gondok yang berpotensi menggangu arus transportasi sungai dan mengundang sampah

3) Sebagian besar mitra terutama ibu rumah tangga, tidak memiliki pekerjaan (non produktif secara ekonomi)

4) Mitra tidak memiliki kemampuan pemasaran dan promosi yang baik

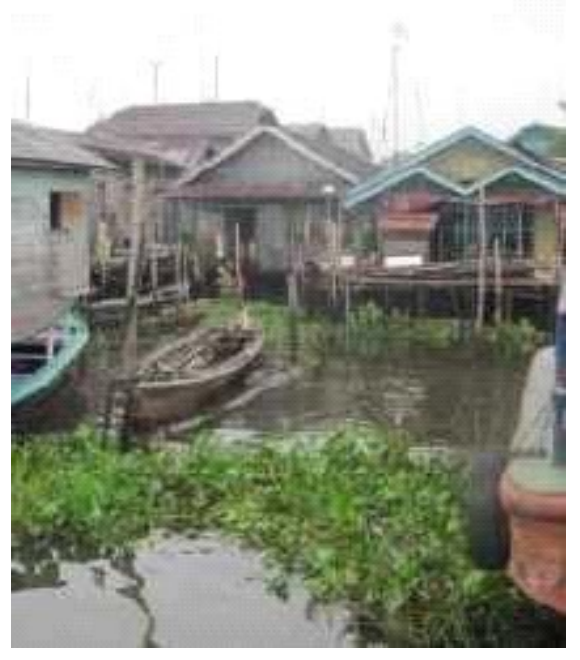

Gambar 1 Eceng Gondok di perairan Sungai Barito

(sumber: ipitojourno.wordpress.com)

\section{Tujuan dan Manfaat Kegiatan}

Tujuan dari kegiatan pengabdian masyarakat ini adalah:

1. Melaksanakan Sosialisasi kepada masyarakat desa Jelapat I akan pentingnya kebersihan sungai

2. Melaksanakan Workshop agar masyarakat bisa mengolah eceng gondok yang selama ini dianggap gulma menjadi barang barang kerajinan yang bernilai ekonomis

3. Melaksanakan Workshop bagi masyarakat agar memiliki kemampuan memasarkan hasil kerajinan yang diolah dari eceng gondok tersebut

Dengan dilaksanakannya kegiatan ini, diharapkan dapat memberikan manfaat sebagai berikut:

1. Membangun kesadaran masyarakat akan pentingnya kebersihan sungai sebagai tumpuan kehidupan masyarakat

2. Masyarakat mampu mengolah eceng gondok yang selama ini menjadi gulma di perairan sungai mereka menjadi bahan bahan kerajinan yang bernilai ekonomis

3. Masyarakat mampu mempromosikan dan memasarkan hasil kerajinan olahan mereka dari eceng gondok tersebut melalui media sosial dan situs-situs penjualan online 


\section{METODE KEGIATAN}

Untuk membantu permasalahan yang dihadapi mitra, tim melaksanakan beberapa kegiatan sebagai berikut:

1) Sosialisasi kepada mitra tentang pentingnya menjaga kebersihan sungai, dan membuka wawasan mitra bahwa eceng gondok yang selama ini dianggap sebagai penggangu sebenarnya dapat dimanfaatkan dan mampu memberikan nilai ekonomis bagi mitra

2) Workshop pengolahan eceng gondok menjadi barang kerajinan.

Pada kegiatan ini, proses pengolahan eceng gondok yang akan diberikan adalah:

a. Pengumpulan Enceng Gondok

Pengumpulan eceng gondok dapat dilakukan dengan mengambil eceng gondok yang banyak di sungai barito. Proses pengumpulan eceng gondok dari sungai ini mempunyai manfaat tambahan selain bermanfaat untuk bahan kerajinan juga bermanfaat membersihkan sungai sekaligus mencegah banjir yang mungkin datang karena akibat yang kontra produktif tanaman eceng gondok ini.

b. Pencucian Enceng Gondok

Setelah eceng gondok dikumpulkan kemudian perlu dicuci untuk menghilangkan kotoran dan bau, caranya dengan dibanting banting sambil diguyur dengan air.

c. Pemisahan Enceng Gondok Dari Daun

Eceng gondok perlu dipilah antara daun dan batang sesuai keperluan bahan kerajinan

d. Pengeringan Enceng Gondok

Setelah dikelompokkan, eceng gondok dijemur untuk dikeringkan

e. Proses Menganyam Batang Eceng Gondok

Untuk bagian batangnya, setelah kering kemudian dianyam sebelum diolah menjadi barang kerajinan.

f. Pembatan Pola

Pembuatan pola sesuai dengan bentuk barang yang akan dibuat, apakah akan dibuat menjadi tas, sepatu, sandal atau aksesoris lainnya. Untuk proses ini perlu dibuat cetakan atau pallet sesuai dengan bentuk yang diinginkan

g. Tahap Akhir

Tahap akhir berupa fisnishing produk, seperti pewarnaan dengan minyak cat atau pernis, atau dilukis agar lebih indah.

3) Workshop kiat promosi penjualan barang kerajinan hasil pengolahan eceng gondok, baik dalam bentuk tips pengemasan dan promosi pada media sosial. Workshop ini diharapkan dapat membantu mitra untuk proses promosi dan penjualan produknya.

\section{HASIL DAN PEMBAHASAN}

\section{Kegiatan Penyuluhan tentang Kebersihan Sungai dan Potensi Eceng Gondok}

Pada kegiatan ini dilaksanakan penyuluhan kepada masyarakat tentang pentingnya kebersihan sungai yang merupakan tulang punggung kegiatan sehari 
hari masyarakat desa jelapat I. Masyarakat desa jelapat I menggunakan sungai sebagai sarana transportasi utama menggunakan feri, kelotok atau jukung, karena akses melalui sungai ke pusat kota Banjarmasin jauh lebih cepat ketimbang lewat darat yang bisa memakan waktu 4 sampai 5 kali lipat. Selain itu, masyarakat juga masih memanfaatkan air sungai untuk keperluan mandi, cuci dan kakus (MCK). Oleh karena itu, kebersihan sungai sangat penting untuk menunjang kelancaran transportasi dan kesehatan warga.

Eceng gondok selama ini oleh warga jelapat I dianggap sebagai tanaman yang sangat menggangu, terutama pada musim penghujan dimana populasi eceng gondok meningkat bahkan sampai menutup permukaan air sungai. Padahal eceng gondok dapat dimanfaatkan sebagai bahan kerajinan. Oleh karena itu dalam penyuluhan ini diperkenalkan beberapa contoh barang kerajinan yang dapat diolah dari eceng gondok

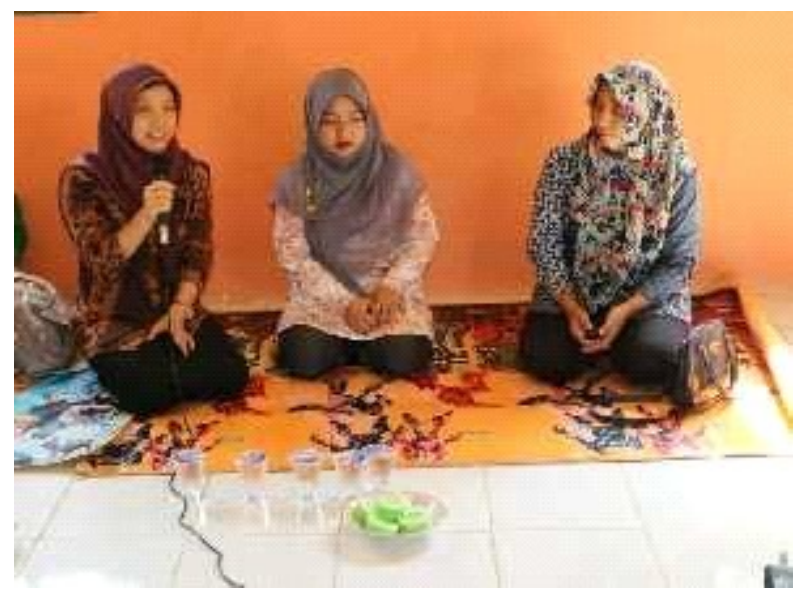

Gambar 2 Kegiatan Penyuluhan pada masyarakat akan pentingnya kebersihan sungai

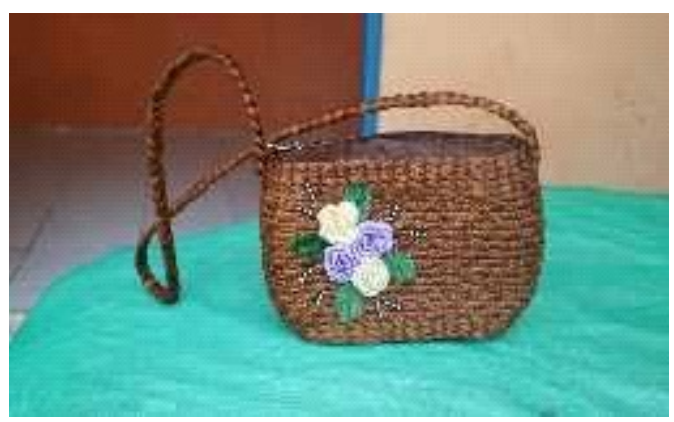

Gambar 3. membuka wawasan mitra bahwa eceng gondok memiliki potensi menjadi barang yang bernilai ekonomis dengan menunjukkan barang jadi 


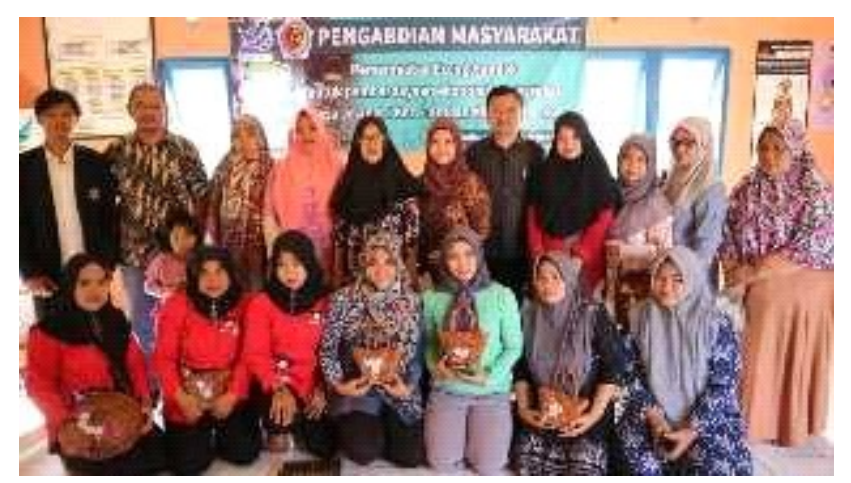

Gambar 4 Bersama mitra penyuluhan dengan contoh produk yang bisa dihasilkan dari eceng gondok

\section{Kegiatan Workshop Pengolahan Eceng Gondok menjadi Barang kerajinan}

Langkah selanjutnya adalah dengan memberikan workshop pengolahan eceng gondok menjadi barang kerajinan. Bertindak sebagai Instruktur pada workshop ini adalah Ibu Siti Nor Sehat dan Ibu Hj. Noor Aida yang merupakan pengrajin sekaligus Pengusaha Eceng gondok dari daerah Hulu Sungai Tengah, dengan didampingi oleh dosen dosen Politeknik Negeri Banjarmasin yang melaksanakan Pengabdian masyarakat. Pada saat acara penyulusah sebelumnya telah diajarkan proses pembersihan dan penjemuran eceng gondok. Sehingga pada workshop ini telah tersedia bahan berupa eceng gondok kering yang siap diolah menjadi barang kerajinan. Peralatan penunjang untuk mengolah barang kerajinan ini adalah gunting dan cetakan (pallet) sederhana.Seluruh bahan dan peralatan untuk peserta workshop disediakan oleh panitia pengabdian masyarakat Poliban.

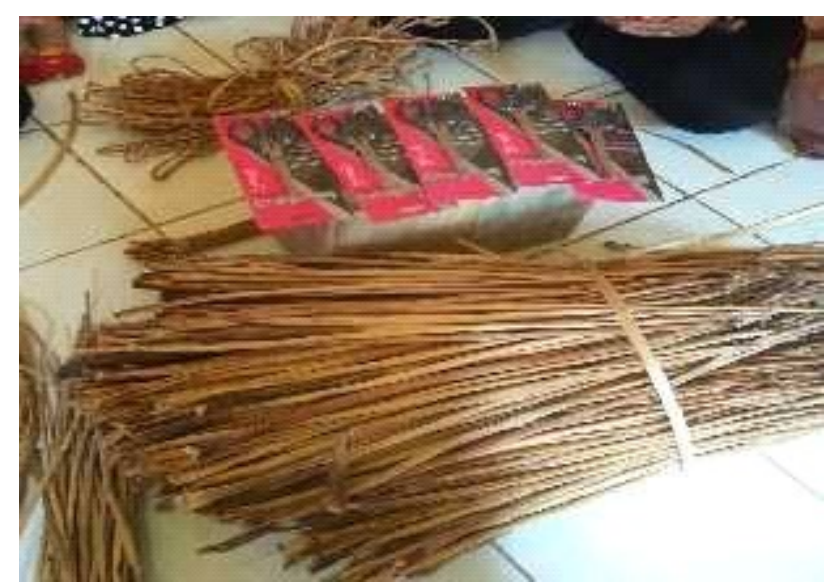

Gambar 5. Bahan dan peralatan workshop berupa eceng gondok kering, pallet dan gunting 


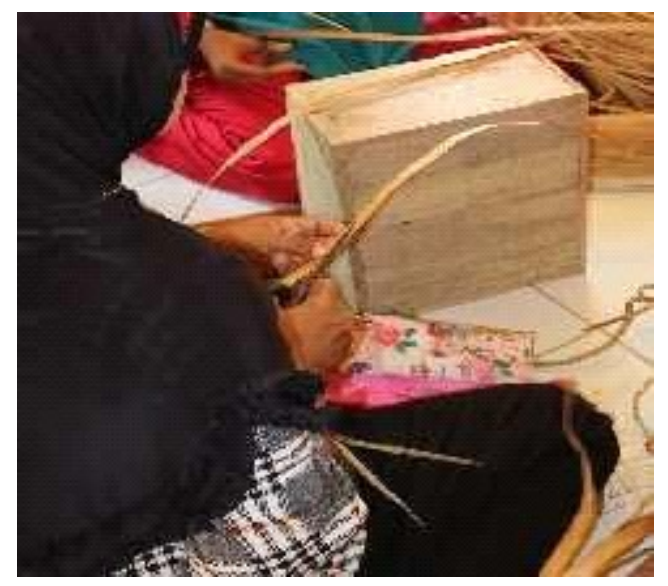

Gambar 6. Pallet sederhana dari kayu berbentuk kotak

Selama Workshop berlangsung seluruh peserta begitu antusias mengikuti pelatihan

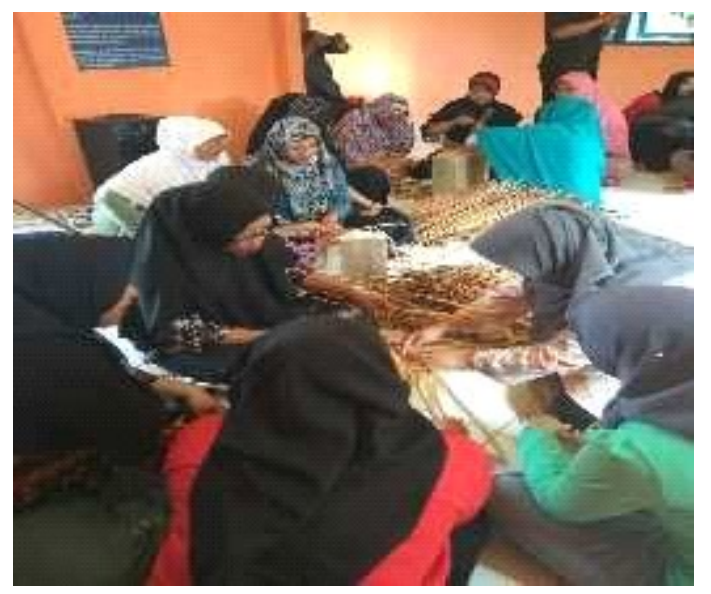

Gambar 7 a. Antusiasme mitra dalam mengikuti workshop

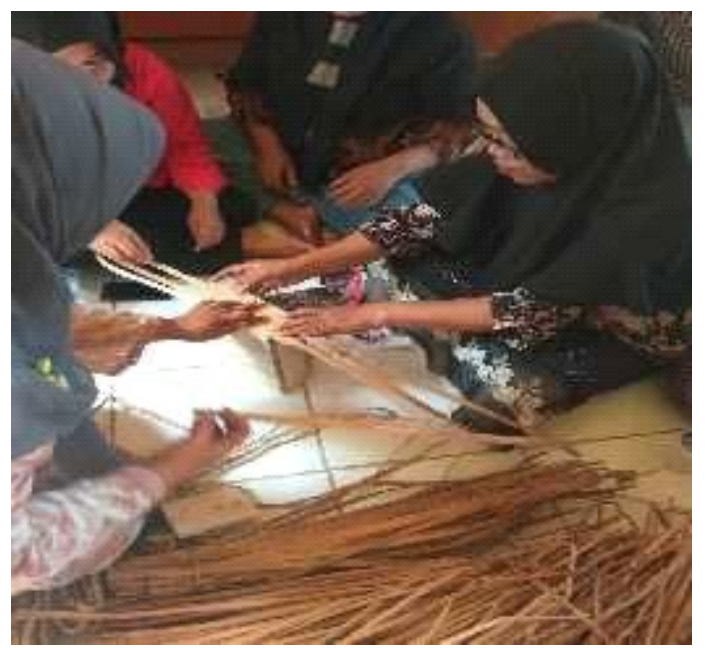

Gambar 7. b. Antusiasme mitra dalam mengikuti workshop 


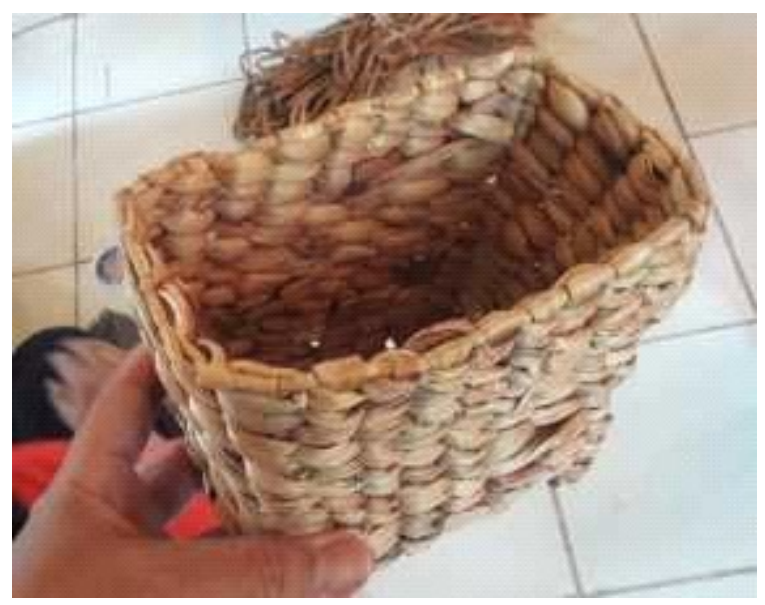

Gambar 8. Hasil Kelompok Pertama, sebelum fisnishing

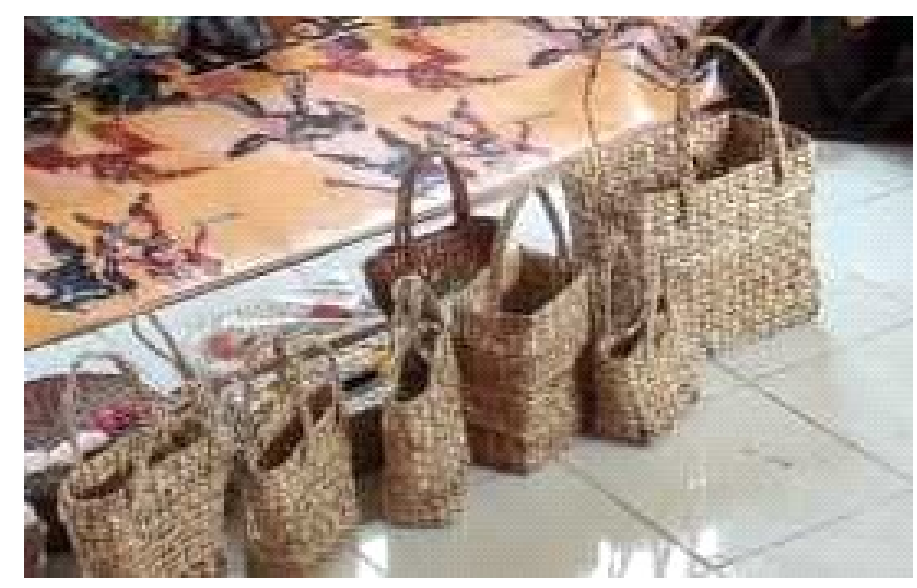

Gambar 9. Hasil kerajinan mitra

\section{Kegiatan Workshop Promosi dan Pemasaran Hasil Kerajinan}

Workshop Pelatihan eceng gondok juga diikuti dengan workshop lain yang tidak kalah penting yakni cara promosi dan pemasaran. Agar hasil olahan eceng gondok yang dibuat mitra binaan dapat menambah penghasilan, perlu dipromosikan dan dipasarkan. Untuk itu, tim pengabdian masyarakat bekerjasama dengan instruktur pelatihan yang sekaligus pengusaha kerajinan Eceng gondok yang telah memiliki jaringan penjualan yang cukup luas. Selain itu tim pengabdian masyarakat juga mengajarkan cara cara promosi dan penjualan melalui media sosial seperti facebook dan instagram dan situm penjualan online seperti shopee dan bukalapak. 


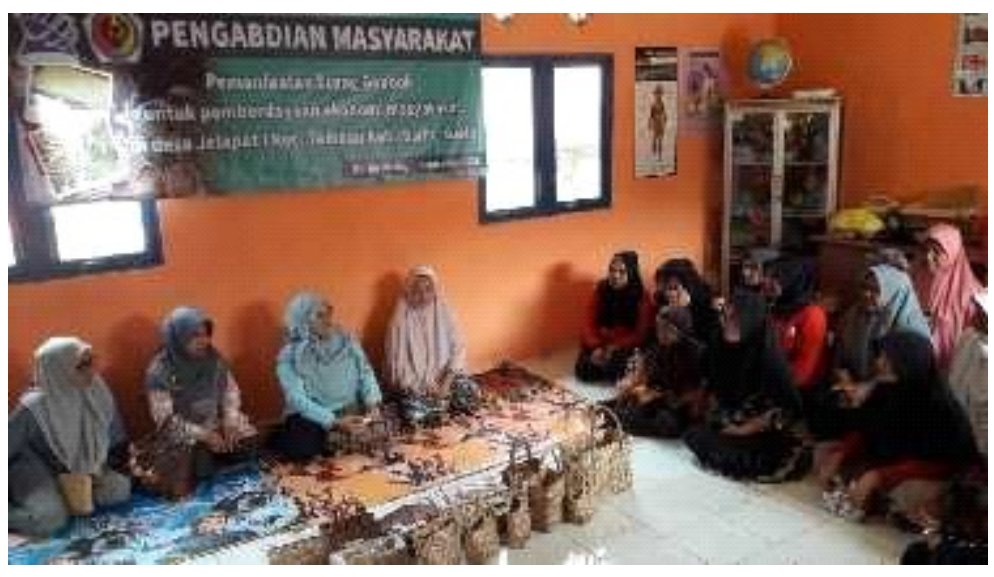

Gambar 10. Kesepakatan penyaluran hasil kerajinan warga melalui pengusaha kerajinan dari daerah HST

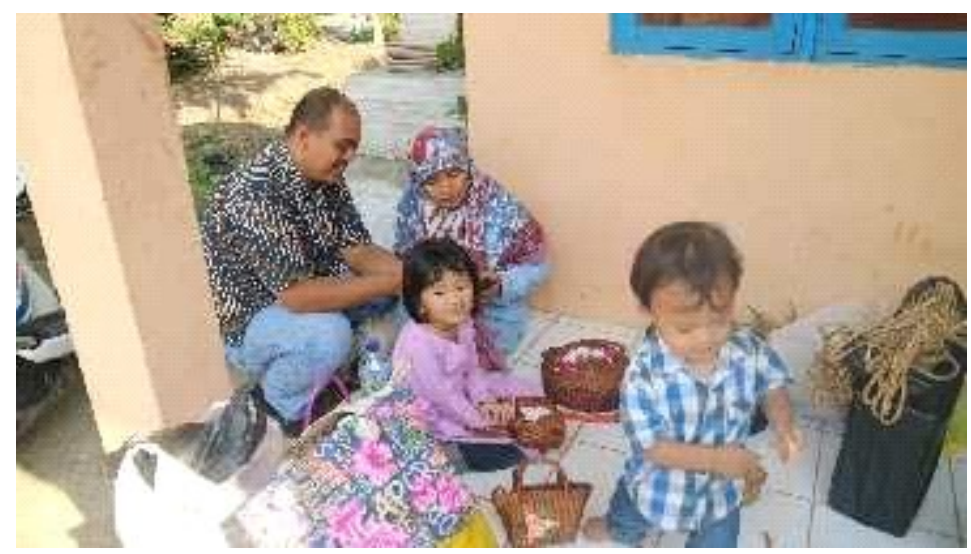

Gambar 11. Tim pengabdian Masyarakat juga mengajarkan penggunaan media sosial dan situs penjualan online untuk media promosi dan penjualan

\section{KESIMPULAN}

Rangkaian kegiatan pengabdian masyarakat di desa Jelapat I berupa Penyuluhan pentingnya menjaga kebersihan sungai, Workshop pengolahan eceng gondok menjadi barang kerajinan, serta workshop promosi dan pemasaran hasil kerajinan melalui media sosial telah selesai dilaksanakan.

Melalui kegiatan penyuluhan, masyarakat telah memahami tentang pentingnya menjaga kebersihan sungai mereka, karena sebagian besar penduduk desa mmang bertunpu pada sungai.

Melalui kegiatan workshop, masyarakat telah mampu memanfaatkan eceng gondok yang selama ini dianggap sebagai gulma menjadi barang kerajinan yakni tas dengan beberapa bentuk dan ukuran.

Melalui kegiatan workshop, masyarakat sudah bisa menggunakan media sosial seperti facebook dan shopee untuk mempromosikan hasil kerajinan mereka. 


\section{DAFTAR PUSTAKA}

(2018). Pasok Anyaman Eceng Gondok Ke Bali. Kalimantan Pos

Ayunasti, (2014). Membuat Kerajinan Tangan dari Eceng Gondok. 15 mei 2018 https://ayunasti.wordpress.com/2014/03/07/cara-membuat-kerajinantangan- dari-tanaman-eceng-gondok/

Rapitasari, D., \& Amirullah, A. (2016). IPTEKS BAGI MASYARAKAT (IbM) PEMBERDAYAAN USAHA KERAJINAN TANGAN ECENG GONDOK "SULAM PITA” BERNILAI EKONOMIS TINGGI DI KELURAHAN KEBRAON KECAMATAN KARANGPILANG KOTA SURABAYA.

Zainuddin, H., (2017). DAS Barito Tak Sejaya Dulu Lagi. 15 Mei 2018 https://hasanzainuddin.wordpress.com/tag/sungai- barito/ 